\section{Made in China: the coronavirus that killed millions of people}

Published online first on December 22, 2021. DOI: 10.20529/IJME. 2021.098

Keywords: coronavirus, gain-of-function studies, furin cleavage site, Covid-19, lab leak

It has been widely suspected that SARS-CoV-2, the coronavirus that caused the Covid-19 pandemic, escaped from the Wuhan Institute of Virology because of sloppy safety procedures and that it was man-made as part of the so-called gain-of-function research at the institute (1). If this is the case, it makes China responsible for over 5 million deaths so far and the United States complicit, as it funded the highly dangerous research (1). The public has been misled about the likely origins of the pandemic right from the start (2).

The best article I have found on this issue was published in the Bulletin of the Atomic Scientists (1), a journal doctors do not read, and I therefore wish to draw attention to its key arguments below.

SARS-CoV-2 has a pair of arginine codons that are routinely used in labs (1). If the emergence were natural, it would require a recombination event at a site on the virus's genome where recombinations are rare, and the insertion of a 12nucleotide sequence with a double arginine codon unknown in the beta-coronavirus repertoire, at the only site in the genome that would significantly expand the virus's infectivity (1). This sequence of events is extremely unlikely, and adding a furin cleavage site is known to make a virus more deadly (1).

Chinese researchers have failed to find a bat population as the source of SARS-CoV-2, or an intermediate host to which SARS-CoV-2 might have jumped (1) despite an intensive search that included the testing of 80,000 animals (3).

A sound principle in research is that if you have nothing to hide, then hide nothing. It can only be beneficial to be open and transparent, as it will increase your trustworthiness. However, China did its utmost to conceal the nature of the tragedy and China's responsibility for it (1). Chinese authorities suppressed all records at the Wuhan Institute and closed down its database of viral genomes (4). China barred all international scientists from going near the caves in Yunnan; blocked the roads; confiscated samples taken by a team of scientists on a trip to the caves; and decreed that all research papers based on evidence from the caves must be submitted to a task force overseen by the government "under direct orders from President Xi Jinping" (5).
The World Health Organization's (WHO) inspection to Wuhan was a farce. It was heavily criticised by some of the world's top virus researchers who wrote that the information, data, and samples for the study were collected and summarized by the Chinese half of the team, and the rest of the team built on this analysis. Although no findings were presented in clear support of either theory, the team assessed a zoonotic spill over from an intermediate host as 'likely to very likely,' and a laboratory incident as 'extremely unlikely'. (6)

However, the two theories were not given equal consideration, which was elucidated in a brilliant TV documentary about WHO's mission to China from August 2021. The film shows the scale and nature of the systematic Chinese cover up about the origin of SARS-CoV-19. The head of the mission, the Dane Peter Ben Embarek, was unusually outspoken and direct for a long-time WHO employee. I have provided a comprehensive summary, with the Danish bits translated into English (7). The documentary ends by saying that WHO has come up with a plan for further studies in China, including in-depth investigations of relevant laboratories in Wuhan. Ghebreyesus, WHO's Director-General said: "We are asking actually China to be transparent, open and cooperate." Zeng Yixin, vice minister in the National Health Commission, China, responded:"I feel that the plan ignores common sense. It defies science."

In science, we should draw conclusions based on what is most likely. It is by far the most likely explanation that the pandemic is not a natural one but is caused by a man-made virus that escaped from a laboratory in Wuhan (1).

It is clear that if the Wuhan Institute had not conducted gainof-function experiments, and therefore had not collected over 1000 samples of coronaviruses from bat caves in Yunnan 1500 $\mathrm{km}$ away from the outbreak in Wuhan (1), there would have been no pandemic.

This type of research should never have been funded and should never have been performed. The WHO and the United Nations should issue a call to stop such research permanently. All governments should make it illegal, with stiff penalties for breaking the law. This research is a great threat to mankind and must stop.

Competing interests and funding: None declared.

Peter C Gøtzsche (pcg@scientificfreedom.dk), Institute for Scientific Freedom, 2970 Hørsholm, DENMARK.

\section{References}

1. Wade N. The origin of COVID: Did people or nature open Pandora's box at Wuhan? Bulletin of the Atomic Scientists. 2021 May 5[cited 2021 May 22\}. Available from: https://thebulletin.org/2021/05/the-originof-covid-did-people-or-nature-open-pandoras-box-at-wuhan. 
2. Calisher C, Carroll D, Colwell R, Corley RB, Daszak P, Drosten C, et al. Statement in support of the scientists, public health professionals, and medical professionals of China combatting COVID-19. Lancet. 2020;395:e42-3.

3. Woodward A. The coronavirus likely traveled 800 miles to Wuhan from farms that breed wild animals for food, a WHO report found. Business Insider. 2021 Mar 31 [cited 2021 May 21]. Available from: https://www.businessinsider.in/science/news/the-coronaviruslikely-traveled-800-miles-to-wuhan-from-farms-that-breed-wildanimals-for-food-a-who-report-found/articleshow/81770095.cms.

4. Segreto R, Deigin Y. The genetic structure of SARS-CoV-2 does not rule out a laboratory origin: SARS-COV-2 chimeric structure and furin cleavage site might be the result of genetic manipulation. Bioessays. 2021;43:e2000240. Available from: https://www.ncbi.nlm.nih.gov/
pmc/articles/PMC7744920/

5. Bostock B. China is guarding ancient bat caves against journalists and scientists seeking to discover the origins of the coronavirus. Insider. 2020 Dec 30 [cited 2021 May 21]. Available from: https:// www.businessinsider.com/china-policing-bat-caves-scientists-hopecoronavirus-clues-inside-2020-12? $r=U S \& \mid R=T$.

6. Bloom JD, Chan YA, Baric RS, Bjorkman PJ, Cobey S, Deverman BE, et al. Investigate the origins of COVID-19. Science. 2021May 14;372(6543): 694.

7. Gøtzsche PC. The head of WHO's COVID-19 mission reveals China's total cover up on Danish TV. Institute for Scientific Freedom. 2021 Aug 21 [cited 2021 Aug 21]. Available from: https:// www.scientificfreedom.dk/2021/08/20/the-head-of-whos-covid-19mission-reveals-Chinas-total-cover-up-on-danish-tv/. 